\title{
Challenges and outcome of total hip arthroplasty in patients with developmental dysplasia of the hip: a clinical series with a spectrum of disease manifestation and technical notes
}

\author{
E. G. Mohan Kumar, G. M. Yathisha Kumar*, Mohammed Noorudheen
}

Department of Orthopedic Surgery, KIMS Al Shifa Hospital, Perintalmanna, Kerala, India

Received: 23 November 2017

Revised: 27 December 2017

Accepted: 28 December 2017

\section{*Correspondence:}

Dr. G. M. Yathisha Kumar,

E-mail: yathishishere@gmail.com

Copyright: (C) the author(s), publisher and licensee Medip Academy. This is an open-access article distributed under the terms of the Creative Commons Attribution Non-Commercial License, which permits unrestricted non-commercial use, distribution, and reproduction in any medium, provided the original work is properly cited.

\begin{abstract}
Patients with developmental dysplasia of hip eventually lead on to secondary osteoarthritis in adulthood and may end up with total hip arthroplasty at a younger age. Because of the altered anatomy of dysplastic hips, total hip arthroplasty in these patients is a technically demanding procedure. Altered anatomy of the acetabulum and proximal femur together with leg length discrepancy pose challenges during total hip arthroplasty. Since the majority of the patients are in the younger age group, soft tissue balance is of great importance to maximise postoperative functional result and longevity of prosthesis. In this paper, we present a series of our patients with a spectrum of disease manifestation from mild to severe form and also discuss the associated challenges and the technical solutions and their outcome.
\end{abstract}

Keywords: Hip, Arthroplasty, Dysplasia, Reconstruction, Techniques, Acetabulum, Femur, Osteoarthritis, Subtrochanteric shortening osteotomy, Developmental dysplasia of the hip

\section{INTRODUCTION}

The end stage sequelae of DDH is more frequently encountered in developing countries due to lack of hip screening and early active treatment of developmental dysplasia of the hip (DDH) and ultimately requiring total hip replacement (THR). These patients are often young and the procedure is technically challenging. ${ }^{1,3}$ Many studies have highlighted the difficulty in regard to preoperative planning, preparing of the true acetabulum, restoration of the offset, and the correction of limb length discrepancy (LLD). ${ }^{3,4}$

Total arthroplasties are especially indicated for painful arthritis of the neoacetabulum (contact dislocations). In the high forms without contact, pain may develop due to contact between the femoral head and the iliac ala, which may be seen on CT Scan. Hip arthroplasty for developmental dysplasia of the hip is a technically complex surgical procedure because of the anatomical changes of acetabulum and proximal part of the femur. Soft tissue contractures and laxity can be present as a result of the acetabular and proximal femoral anatomical variations. Patients with dysplasia require arthroplasty in younger age than the others with osteoarthritis. For this reason, implant selection is an important issue. Bearing surfaces alternative to the conventional metal on polyethylene should be preferred in this young patient population.

We present the outcome of total hip arthroplasty in a series of patients with a varying spectrum of disease at presentation and the challenges associated, the surgical options to be considered and common complications associated with this procedure. 


\section{CLINICAL SERIES}

\section{Case 1}

A 28-years-old female presented to us with limping since childhood and pain in left hip for 2 years. The pain was insidious in onset and gradually progressive serious enough to limit her activities of daily living. X-ray showed Crowe type two DDH left hip with arthritis (Figure 1A). This is a milder form of the disease and the challenges in this patient for total hip arthroplasty were coxa valga and deficient anterior superior acetabular wall. Here we planned for uncemented THR with oxynium on poly bearing surfaces using standard implants, did preoperative templating. Our aim was to go to the anatomical hip center. So hip center was brought down and the cup was medialised (Figure 1B). The offset was restored by a high neck cut and using standard offset stem. The patient was made ambulant on $2^{\text {nd }}$ postoperative day with partial weight bearing using a walker for one month and full weight bearing with a cane for 1 months. At one year follow up the patient is doing well.

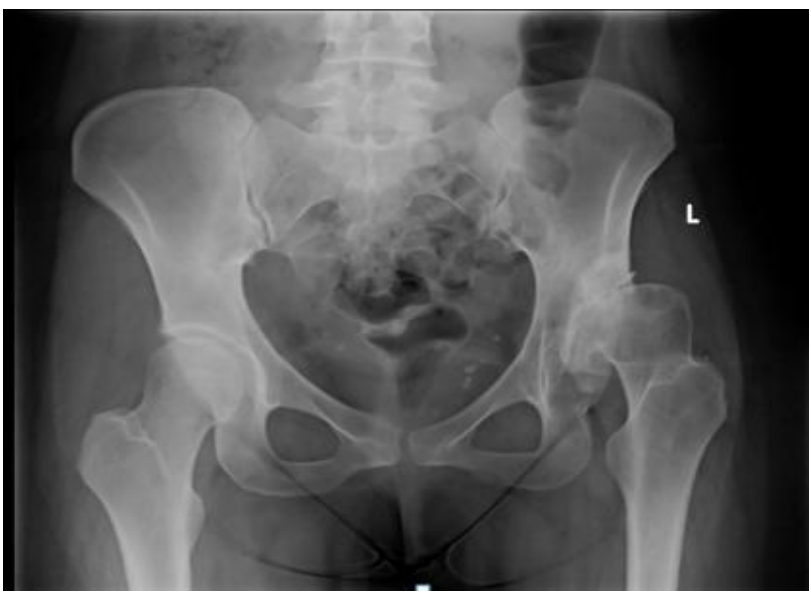

Figure 1 (A): Crowe type II DDH left hip.

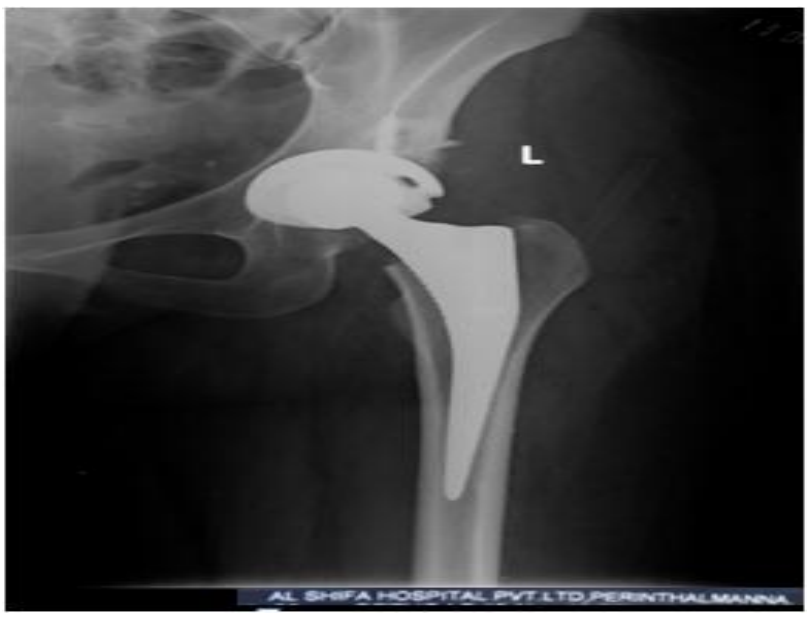

Figure 1 (B): Post operative.

\section{Case 2}

Another patient (Figure $2 \mathrm{~A}$ and B) a 38-year-old female presented to us with Crowe type II DDH. We could restore the anatomy with a similar procedure.

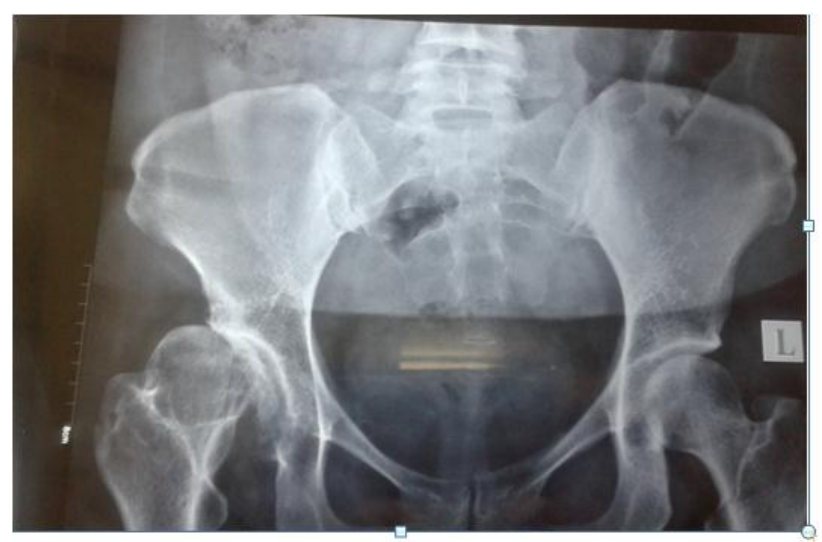

Figure 2 (A): Crowe type II DDH right hip.

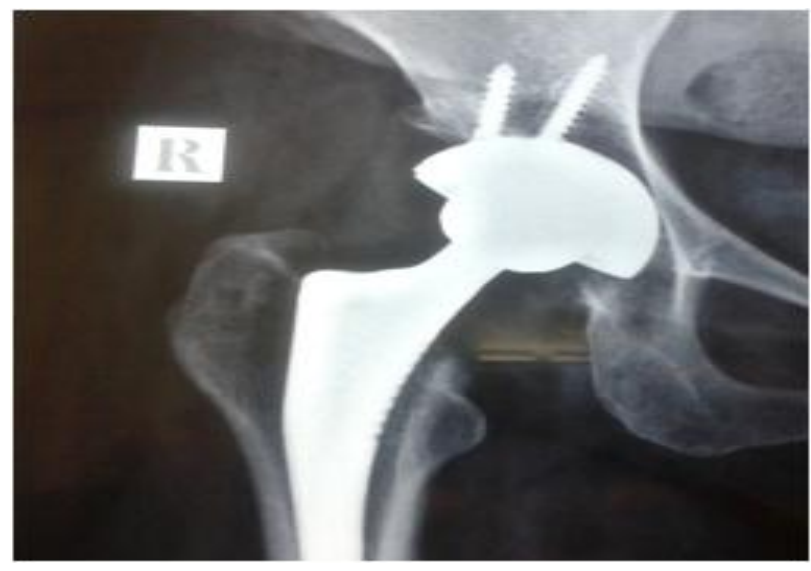

Figure 2 (B): Post operative.

Case 3

A 40 years old obese female patient presented to us with limping pain right hip. She noticed pain in right hip since one year. On presentation, the pain was limiting her activities of daily living. X-ray showed Crowe type III DDH right hip with low dislocation (Figure 3A). CT scan confirmed there was a shallow acetabular cavity, deficient anterio-superior wall and hypoplastic proximal femur (Figure 3B). Here we planned for uncemented THR using a standard prosthesis. It is advised to keep a backup of modular implants and cemented version. Challenges here are obesity, low hip dislocation, absent acetabulum, hypoplastic femur, coax valga, lax hip. We aimed at anatomical hip center. Usually, we get a strong bone at native acetabulum and a controlled violation of medial wall is sometimes required to get purchase. We should aim at a minimum of $20^{\circ}$ anteversion of the cup to avoid too much of the anterosuperior wall being kept uncovered. The offset is restored with high neck cut and proud position of the stem (Figure 3C). The release of 
iliopsoas for reduction may be required. Postoperative protocol was same as in case 1 and at 2 years follow up the patient is doing well.

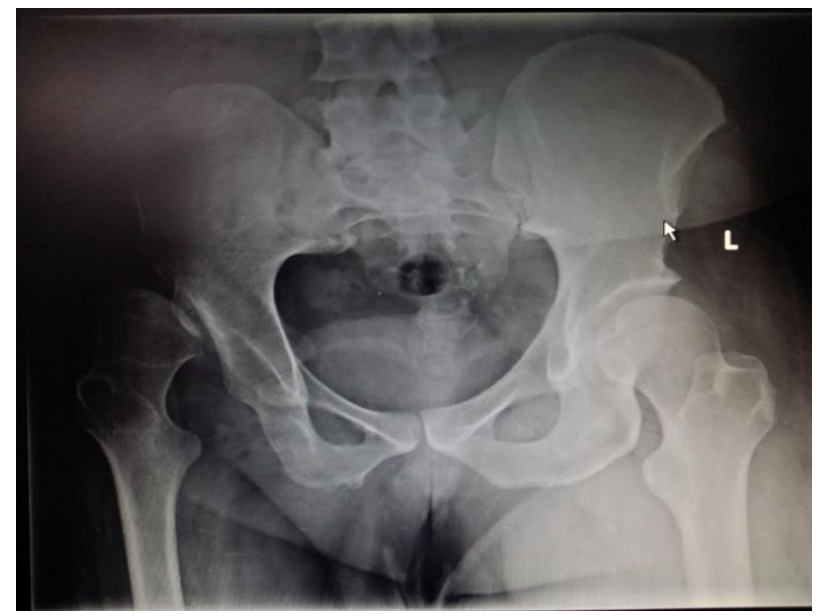

Figure 3 (A): Crowe type III DDH right hip.

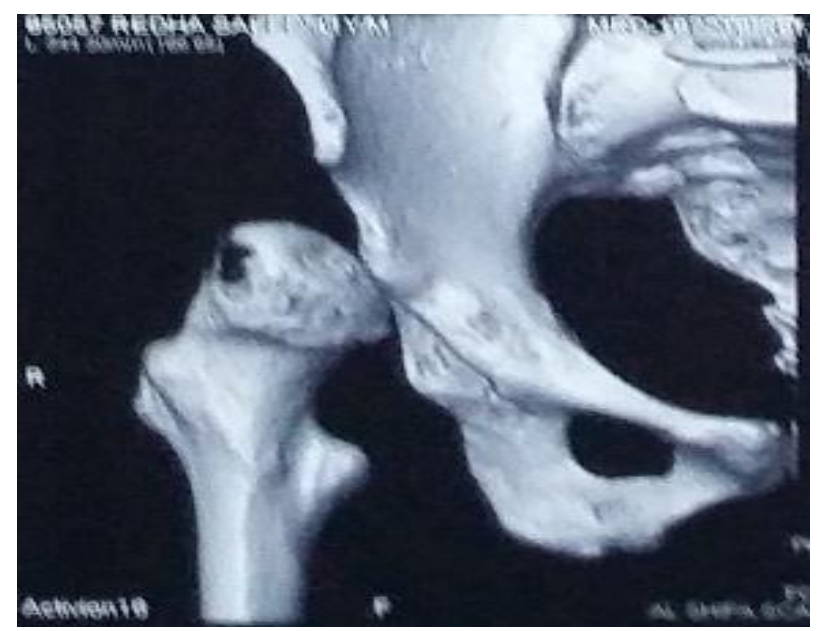

Figure 3 (B): Pre-op CT showed shallow and anterosuperior bone deficiency of acetabulum low dislocation hip, coax calga.

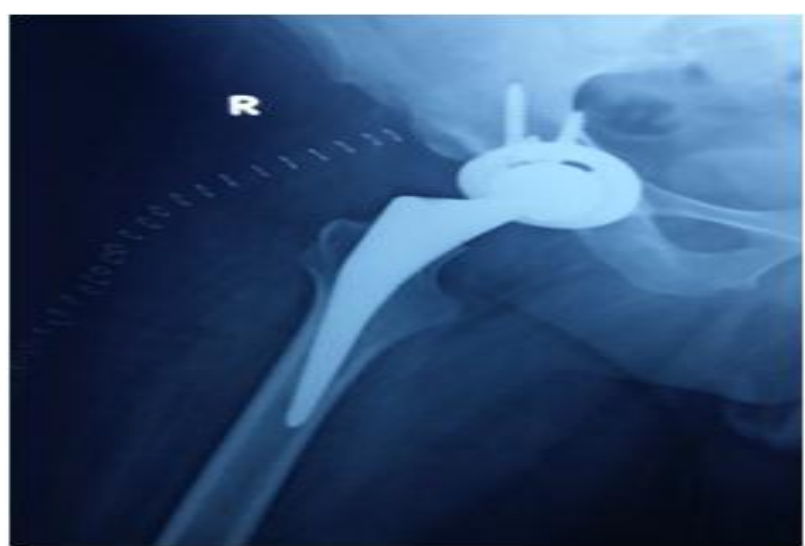

Figure 3 (C): Post-op x-ray note the anteverted cup insertion, controlled cotyloplasty done to get stability, proud insertion of femoral stem to restore offset.

\section{Case 4}

A 30 years old female presented to us with limping and pain in bilateral hips. The pain was since four years more in right hip which was limiting her activities of daily living. X-ray showed Crowe type III DDH in right hip and Crowe type II DDH in left hip with advanced arthritis in both hips (Figure 4A). This patient was operated early in our series. Challenges here include high hip dislocation in right hip, deficient anterosuperior acetabular wall and huge medial osteophytes. We planned uncemented THA in right hip first and left hip was operated 2 months later. In both hips, we aimed at anatomical hip center and reconstructed superior acetabular wall which is optional but it helps in a future revision (Figure 4B). Primary stability of the cup was ensured by good anteriorposterior purchase. When we are not reconstructing the superior wall up to $30 \%$ of the cup can be safely left uncovered. A high hip center up to $2 \mathrm{CM}$ is acceptable in such cases. Again postoperative protocol was same as case 1 at 7 years follow up she is doing well. Similar case with bilateral hip DDH Crowe type III in right hip and type II in left hip (Figure 5A). Here we accepted a high hip center in right hip( Figure 5B). Postoperatively no nerve palsy noted and at 9 years the post-op patient is doing well.

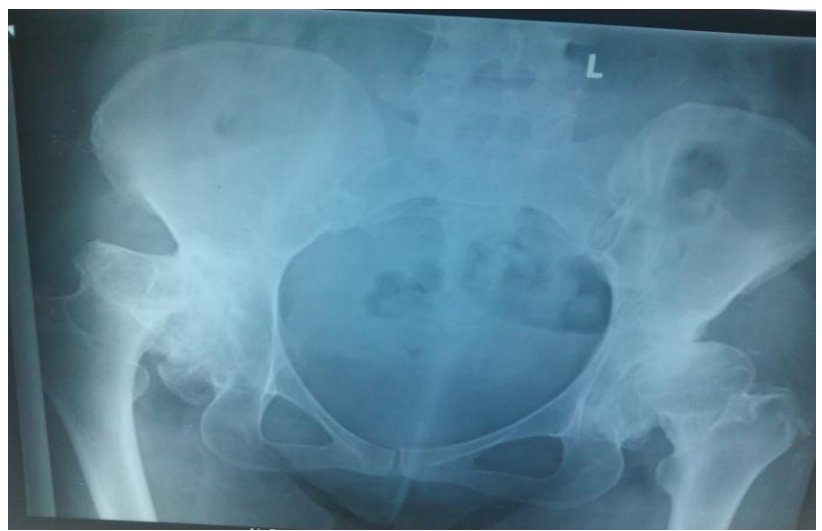

Figure 4 (A): Bilateral DDH- Crowe typeIII (right) type I (left).

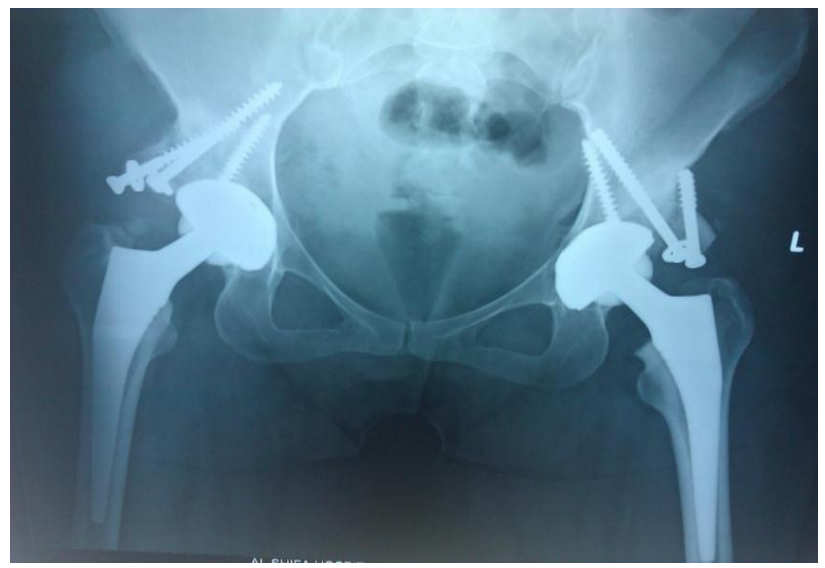

Figure 4 (B): 7 years follow up. 


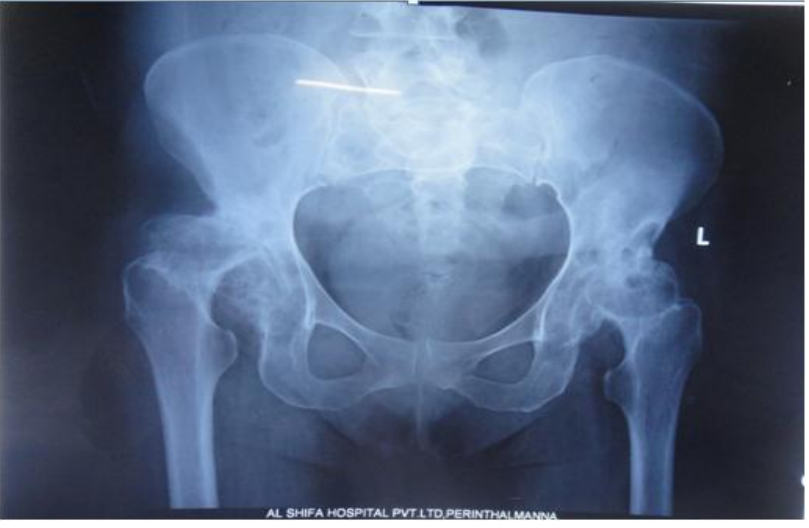

Figure 5 (A): DDH- Crowe type III (right), type II left hip.

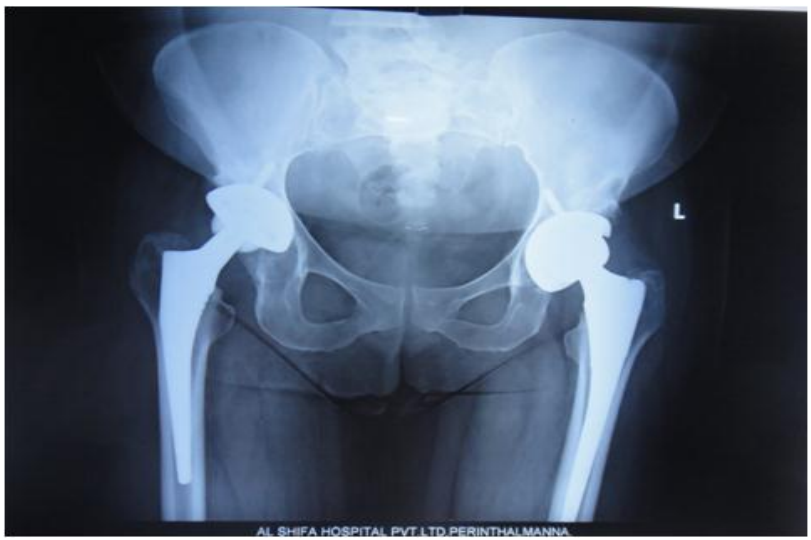

Figure 5 (B): 9 years follow up.

\section{Case 5}

A 21 years old female presented to us with limping of right hip since childhood and pain which started recently. She noticed pain for one year, which was limiting her activities of daily living. She also had $10 \mathrm{CM}$ shortening of right lower limb femoral component. X-ray showed Crowe type IV DDH in right hip (Figure 6A). The challenges are- high dislocation of the hip, hypoplastic acetabulum and femur with narrow canal and adaptively shortened sciatic nerve and all soft tissues around including abductors. We did CT to access the bone stock of acetabulum and status of femoral canal (Figure 6B) Preoperative templating was done. We planned to address this case with a modular prosthesis (S-ROM) with subtrochanteric shortening osteotomy to prevent overstretching of the sciatic nerve, restore hip center and facilitate reduction. Up to $5 \mathrm{CM}$ of lengthening may not result in sciatic nerve palsy. The subtrochanteric osteotomy was done at the level of ischial tuberosity and allowed the femur to overlap. The extent of overlap in traction with hip reduced determines the desired amount of shortening. We restored the anatomical hip center, primary stability of cup was achieved by cotyloplasty, selecting the smallest cup size available, and the cup was inserted with $30^{\circ}$ anteversion and 10 degrees of anteversion was given on femoral side to get the CAVA right (Figure 6C). The proximal fragment had to be split and held with cables to accommodate the smallest implant. Postoperatively touch down weight bearing was allowed for one month and gradually progressed to full weight bearing. Osteotomy united at 3 months. At 1 year follow up, the patient is doing well.

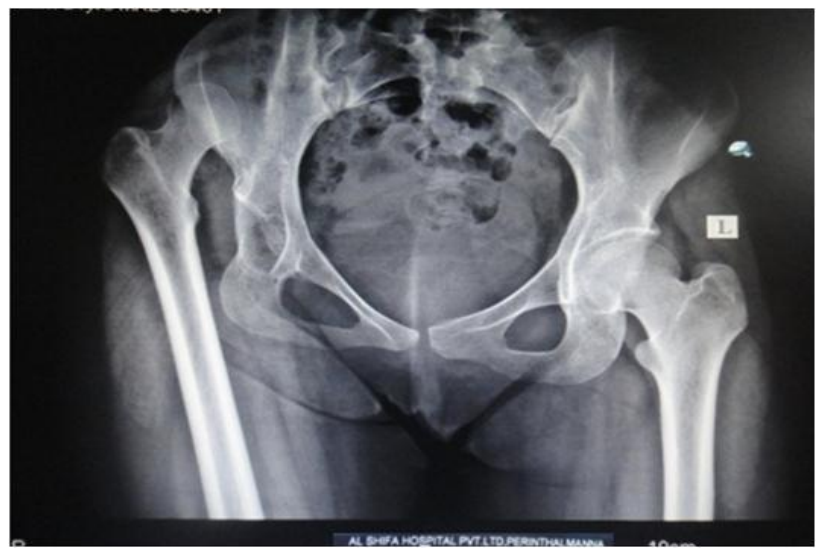

Figure 6 (A): DDH- Crowe type IV right hip with 10 CM shortening.

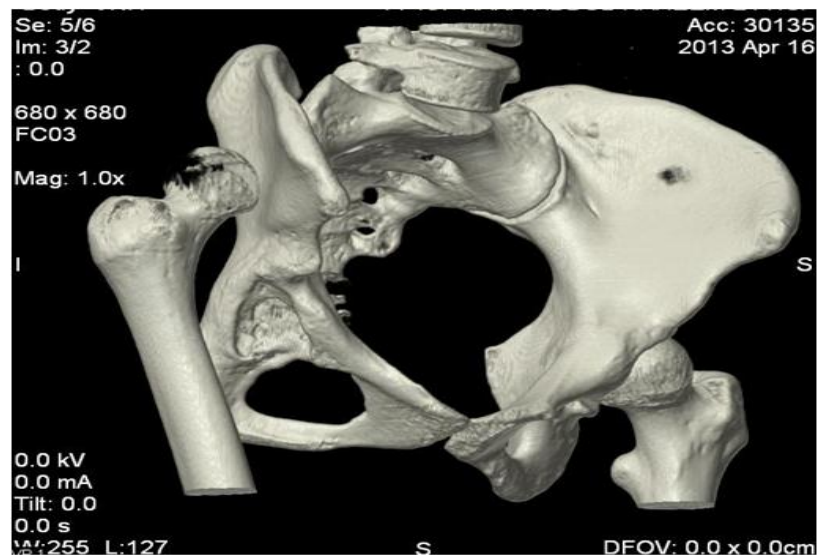

Figure 6 (B): Pre operative CT.

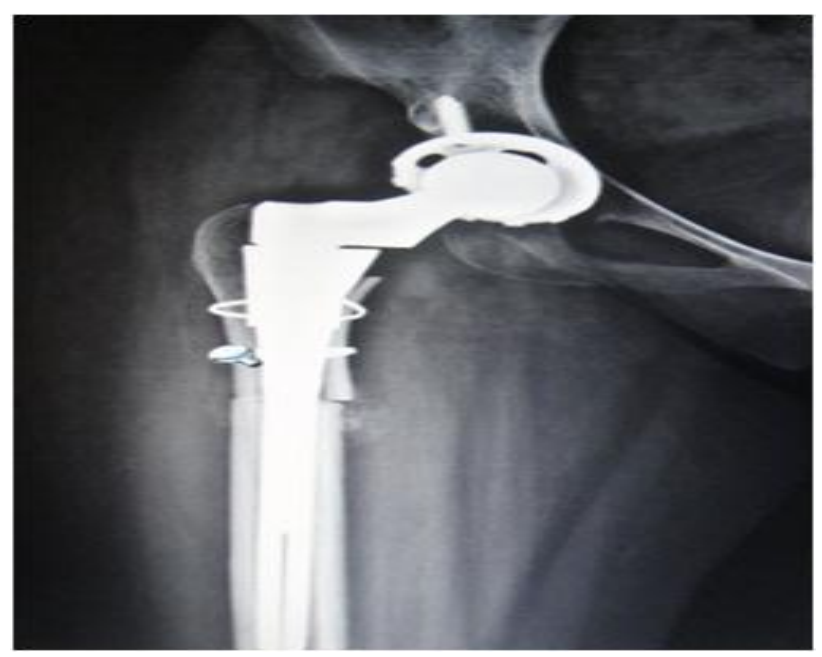

Figure 6 (C): Post operative S ROM stem with subtrochanteric shortening osteotomy. 


\section{DISCUSSION}

Abnormal anatomy in a patient with DDH results in secondary osteoarthritis at a younger age (an average of 53 years according to Hartofilakidis et $\mathrm{al}^{5}$ ). Despite an initial discouraging statement that THR should be avoided in patients who have DDH, various techniques have been developed to approach this problem. ${ }^{6}$ The key point of surgical treatment is to ensure long-term stability of the endoprosthesis by restoration of anatomical and biomechanical relationships. Total hip arthroplasty in DDH is technically demanding due to deficient acetabular bone stock, abnormal femoral anatomy with the increased neck-shaft angle and valgus orientation, increased anteversion, poorly developed medullary canal, muscle shortening and leg-length discrepancy., Distorted anatomy of the acetabulum and proximal femur is always a challenge. Then there is leg length discrepancy. And finally, the soft tissue balance is of great importance (especially the need to preserve the continuity of abductors) to maximise postoperative functional result. ${ }^{8,9}$ Various techniques have been described in the literature (Table 1).

Table 1: Different operative treatment options for total hip arthroplasty in secondary hip osteoarthritis in developmental dysplasia of the hip.

\begin{tabular}{|ll|}
\hline Techniques for acetabular reconstruction & Techniques for femoral reconstruction \\
\hline Standard metal augments (prefabricated) & Distraction with external fixator \\
\hline Custom made acetabular augments (3D printing) & Femoral shortening through a modified lateral approach \\
\hline Roof reconstruction with vascularized fibula & Transtrochanteric osteotomies \\
\hline Roof reconstruction with pedicled iliac graft & Paavilainen osteotomy \\
\hline Roof reconstruction with autologous bone graft & Lesser trochanter osteotomy \\
\hline Roof reconstruction with homologous bone graft & Double-chevron osteotomy \\
\hline $\begin{array}{l}\text { Roof reconstruction with auto/homologous spongious } \\
\text { bone }\end{array}$ & Subtrochanteric osteotomies \\
\hline $\begin{array}{l}\text { Reinforcement ring with the hook in combination with } \\
\text { autologous graft augmentation }\end{array}$ & Diaphiseal osteotomies \\
\hline \begin{tabular}{l} 
Cranial positioning of the acetabulum \\
\hline Medial protrusion technique (cotyloplasty) with chisel
\end{tabular} & Distal femoral osteotomies \\
\hline $\begin{array}{l}\text { Medial protrusion technique (cotyloplasty) with } \\
\text { reaming }\end{array}$ & \\
\hline \begin{tabular}{l} 
Cotyloplasty without spongioplasty \\
\hline
\end{tabular} & \\
\hline
\end{tabular}

\section{Acetabular reconstruction}

The major concern with total hip arthroplasty in DDH is the containment and incorporation of the acetabular cup. Placement of the cup is technically difficult because normal anatomic landmarks are obscured. There is a need for fine balance in adjusting the cup size, inclination, cup anteversion and coverage. A compromise can be made by setting acetabular component away from the ideal center of rotation, but in such a way to ensure a good stability of the endoprosthesis. High placement of the acetabular component has been proposed. Russotti et $\mathrm{al}^{10}$ reports good long-term results with "high hip center". Kaneuji et al claim no difference in polyethylene wear with rotation center placed $20 \mathrm{~mm}$ proximal from the figure of tears. ${ }^{11}$ However, according to Bicanic et al one has to take into account that for every millimeter of proximalisation, the load on the hip increases for about $0.1 \% .^{12}$ At this level bone stock is usually insufficient and the lever arm for body weight remains much longer than that of the abductors, resulting in excessive loading of the hip joint. In addition, at this level, shearing forces acting on the acetabular component may lead to an early loosening, and in unilateral cases, a proximally placed acetabular component contributes to limping and limb-length discrepancy. ${ }^{13,14}$
Placement of the acetabular component in the anatomical position and augmentation of the superior segmental defect with structural autologous graft (autograft) or allograft has also been proposed. Cementless acetabular cups with $30 \%$ to $40 \%$ of un coverage may be acceptable. ${ }^{15-17}$ Some authors recommend spongioplasty of the acetabular roof for smaller uncovered areas. ${ }^{18}$ For larger defects structural autograft or allograft can be used. Autografts can be free or vascularized. Vascularized autograft is expected to integrate better with iliac bone. ${ }^{19}$ Fujiwara reported good outcome of acetabular roof reconstruction with free vascularized fibular graft. $^{20}$ Long-term survival rates of such bone grafts proved to be different in various studies. While some authors report

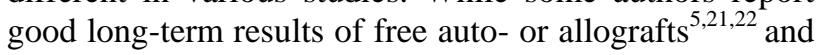
vascularized autografts, others warn about graft resorption and secondary instability of acetabular component in structural bone grafting. ${ }^{20,23-28}$ Acetabular bone stock deficiency can be managed with specially constructed acetabular components or using special 3dimensional porous materials which simulates bone structure and allow faster and better endoprosthesis-bone integration. ${ }^{29-31}$ For that purpose trabecular metal is used in the form of acetabular cup or trabecular metal augments. These are mainly used in revision surgery, but can be useful in dysplastic hip THA. ${ }^{31,32}$ Potential 
advantage of trabecular metal is to avoid the use of structural bone grafts, avoid the need for custom shaped implants and provide excellent bone ingrowth on small contact area. Major disadvantage is potential difficulty if the cup should be removed because of infection. Oblongshaped cementless implant (oblong cup) can be used for acetabular reconstruction. Abeyta et al presented satisfactory long-term results in using oblong cup for reconstruction of the acetabulum. ${ }^{33}$ According to fact that medialisation of acetabular cup decreases hip load and that satisfactory supero-lateral support of the component with host bone is a better option, a method named cotyloplasty was introduced. Later, in 2008 Bicanic et al proved that every millimetre of lateral displacement of the acetabular cup (relative to the ideal centre of rotation) results with an increase of $0.7 \%$ in hip load, and for every millimetre of proximal displacement an increase of $0.1 \%$ in hip load should be expected (or decreased if displacement is medial or distal). ${ }^{12}$ That suggests acetabular placement as far medially as possible for optimal results. Cotyloplasty is a technique that involves making a perforation of the medial wall of a shallow acetabulum and then inserting an acetabular cup with the medial aspect of its dome beyond the Kohler's line. In 1976, Dunn et al presented a method that involved intentional medial wall fracture using osteotome with cup placement beyond the ilioischial line, avoiding bone grafting but still achieving cemented acetabular cup stability. ${ }^{34}$ At the meeting of the Greek Orthopaedic Association in 1984, technique of cotyloplasty for the preparation of the acetabulum was reported by Hartofilakidis et al. ${ }^{35}$ This method involved the use of a T-handle curette to enlarge the socket. When the acetabulum was large enough they fracture the paper-thin medial wall using a deepening reamer. Acetabulum was filled with a large amount of autogenous cancellous bone graft and cup is cemented in position without pressure. Hartofilakidis et al modified this method by perforating the medial acetabular wall with a reamer instead of an osteotome and called the technique cotyloplasty. ${ }^{35,36}$ Satisfactory reports were published later concerning the results of implanting cemented cups using cotyloplasty. Dorr et al reported good results when implanting porouscoated acetabular components using this technique. ${ }^{37}$ Cotyloplasty has advantages over other techniques of fixing an acetabular component in a dysplastic acetabulum. This technique has advantages over superior cup placement because it usually restores the normal hip joint biomechanics, it restores the leg length discrepancy and it has less chance of impingement that may lead to dislocation. Major disadvantage of the cotyloplasty is that it is difficult to control the amount of the medial wall fracture and complication such as -dislocation of the cup inside the pelvis can occur.

\section{In our series}

We have restored anatomical hip reconstruction in all cases of Crowe type I-II and in most of the cases with type III-IV. In one patient with type III DDH, we accepted high hip center (Figure 4B) and she is doing well for 9 years follow up. The superior acetabular wall was reconstructed in one patient using autologous bone graft (Figure 5B) which is optional because cementless acetabular cups with $30 \%$ to $40 \%$ of noncoverage is acceptable.

\section{Femoral reconstruction}

According to the Crowe classification, arthroplasty procedures performed on dysplastic hips that belong to Crowe I or II class allow positioning of the femoral head in optimal hip rotation center without performing any of the femoral shortening procedures. In contrast, arthroplasty procedures performed on Crowe III or IV dysplastic hips commonly require one of the femoral shortening procedures.

After placement of the acetabular component in anatomic position, femur often becomes too long and needs to be shortened. Thus, shortening femoral osteotomies are developed, which further allows: (1) hip arthroplasty without sciatic nerve stretching; and (2) correction of the proximal femoral anteversion. After these procedures are performed, abductor mechanism of the hip is restored with equal final leg length. ${ }^{38}$ Femoral procedures can be roughly divided according to the level of procedure: proximal femur, femoral shaft and distal femoral procedures.

Shortening procedures performed on femoral metaphysis (subtrochanteric osteotomies) are the most frequently used procedures for femoral shortening in DDH. Double Chevron osteotomy was first described by Becker et al in $1995 .^{39}$ Total hip arthroplasty was combined with a femoral subtrochanteric shortening derotational doublechevron osteotomy.Initial results were promising, but this method of Becker and Gustilo did not allow any intraoperative changes and required complex and detailed preoperative planning that was sometimes hard to perform during surgery. Several modification of the first technique is reported so far, such as the one from Li et al where transverse osteotomy was first performed, followed by rotational alignment in order to correct anteversion. $^{40}$ Later, after vertical alignment (length) double chevron osteotomy was performed at the site of the previous transverse osteotomy. Such method allowed more precise (intraoperative) derotation and shortening adjustment. Several authors with several differences in techniques described transverse subtrochanteric osteotomies. First, Reikeraas et al presented transverse osteotomy in 25 cases, with the use of 4 cemented stems and 21 uncemented stems. ${ }^{41}$ Surprisingly, at 3-7 years follow up, $96 \%$ satisfactory results were reported, with no revision procedures or mechanical complications and only 1 delayed union and 1 varus malunion. Similar to this procedure, Yasgur et al reported a modified technique in 1997 with enhanced torsional stability with uncemented fully porous-coated stems, press-fit into the diaphysis and augmented with allograft struts and cables 
on 9 patients. ${ }^{42}$ After 2-7 years period, 1 patient suffered nonunion at the osteotomy site and one had a failure of a distally ingrown porous device, which required revision. Later on, Masonis et al supported the use of a transverse subtrochanteric femoral osteotomy in high DHH with secondary arthritis. ${ }^{43} 5$ years after the procedure was performed, a follow-up report was published where authors concluded that the transverse osteotomy union rate was identical to the report using a step-cut method; On the other side, cemented total hip arthroplasty with subtrochanteric transverse osteotomy for Crowe group IV DDH was described by Kawai et $\mathrm{al}^{45}$ in $2011 .^{44}$ Authors described procedure where shortening osteotomy sites were covered with grafts of the excised fragments fixed with cerclage wires. Authors presented good short-term results without significant complications. Bruce et al reported in 2000 a femoral shortening technique with use of a straight cylindrical prosthesis that acts as an intramedullary nail. ${ }^{46}$ Such prosthesis provides stability control of the distal fragment. First, the femoral osteotomy was performed with prosthesis in situ, then, the prosthesis was advanced distally and morcellized autologous bone-graft was applied to the osteotomy site. In that way, one of the most important complications after femoral shortening procedure(nonunion of the osteotomy site) - was reduced to a minimum. ${ }^{42,45}$ This method has all the characteristics of a simple, reliable and flexible surgical technique. Togrul et al in 2010 presented a similar technique of femoral fixation that uses a transverse osteotomy for subtrochanteric shortening with the use of bone pegs prepared from the resected femoral segments which are then placed in the medullary canal around the stem thus providing femoral fixation. ${ }^{47}$ Authors reported 21 cases with an adequate union present in all cases, and early dislocation in only 2 cases.

Koulouvaris et al reported in 2008 an interesting combined procedure where distal femoral shortening procedure was performed as an addition to THR of dysplastic and difficult-to-reduce hips. ${ }^{48,49}$ One of the major advantages of this technique is the possibility of combined correction of the ipsilateral knee valgus deformity, which can be performed simply by changing the shape of resection fragment.

In our series, we have performed 3 subtrochanteric shortening osteotomy for Crowe type IV DDH. At one year follow up all 3 osteotomies united with good functional outcome. It is advised to keep a backup of modular implants in addressing such cases because of the significant anatomical abnormality of proximal femur usually associated with the very narrow canal.

\section{CONCLUSION}

It is important to understand the complex anatomical changes of acetabulum and proximal part of the femur and soft tissue before considering THR in dysplastic hips. Proper preoperative planning is essential. Preoperative CT scan help in better understanding and planning.
Backup of modular implants and cemented version is mandatory. Anatomical hip reconstruction provides a superior outcome. However, a high hip center up to 20 $\mathrm{mm}$ is acceptable if the hip is not lateralized or there is easy anterior-posterior placement. Anteversion of the acetabular cup should not be less than $20^{\circ}$. Superior acetabular wall reconstruction using autologous bone graft is optional. Cotyloplasty and medicalisation of the cup is a good option for stability and biomechanical consideration. Cementless acetabular cups with $30 \%$ to $40 \%$ of uncoverage is acceptable. The modular prosthesis or distally fixing stems are recommended for Crowe type III-IV DDH. Subtrochanteric shortening osteotomy allows easy reduction and avoids sciatic nerve palsy in high dislocation.

\section{Funding: No funding sources \\ Conflict of interest: None declared \\ Ethical approval: Not required}

\section{REFERENCES}

1. Crowe JF, Mani VJ, Ranawat CS. Total hip replacement in congenital dislocation and dysplasia of the hip. J Bone Joint Surg Am. 1979;61(1):1523.

2. Nagoya S, Kaya M, Sasaki M, Tateda K, Kosukegawa I, Yamashita T. Cementless total hip replacement with subtrochanteric femoral shortening for severe developmental dysplasia of the hip. J Bone Joint Surg Br. 2009;91(9):1142-7.

3. Tabak AY, Celebi L, Muratli HH, Yagmurlu MF, Aktekin CN, Bicimoglu A. Cementless total hip replacement in patients with high total dislocation: the results of femoral shortening by subtrochanteric segmental resection. Acta Orthop Traumatol Turc. 2003;37(4):277-83.

4. Decking J, Decking R, Schoellner C, Fuerderer S, Rompe JD, Eckardt A. Cementless total hip replacement with subtrochanteric femoral shortening for severe developmental dysplasia of the hip. Arch Orthop Trauma Surg. 2003;123(7):35762.

5. Hartofilakidis G, Karachalios T. Total hip arthroplasty for congenital hip disease. J Bone Joint Surg Am. 2004;86-A:242-50.

6. Charnley J, Feagin JA. Low-friction arthroplasty in congenital subluxation of the hip. Clin Orthop Relat Res. 1973: 98-113.

7. Kobayashi S, Saito N, Nawata M, Horiuchi H, Iorio R, Takaoka K. Total hip arthroplasty with bulk femoral head autograft for acetabular reconstruction in developmental dysplasia of the hip. J Bone Joint Surg Am. 2003;85-A:615-21.

8. Delimar D, Bicanic G, Korzinek K. Femoral shortening during hip arthroplasty through a modified lateral approach. Clin Orthop Relat Res. 2008;466:1954-8.

9. Wu X, Li SH, Lou LM, Cai ZD. The techniques of soft tissue release and true socket reconstruction in 
total hip arthroplasty for patients with severe developmental dysplasia of the hip. Int Orthop. 2012;36:1795-801.

10. Russotti GM, Harris WH. Proximal placement of the acetabular component in total hip arthroplasty. A long-term follow-up study. J Bone Joint Surg Am. 1991;73:587-92.

11. Kaneuji A, Sugimori T, Ichiseki T, Yamada K, Fukui K, Matsumoto T. Minimum ten-year results of a porous acetabular component for Crowe I to III hip dysplasia using an elevated hip center. J Arthroplasty. 2009;24:187-94.

12. Bicanic G, Delimar D, Delimar M, Pecina M. Influence of the acetabular cup position on hip load during arthroplasty in hip dysplasia. Int Orthop. 2009;33:397-402.

13. Yoder SA, Brand RA, Pedersen DR, O'Gorman TW. Total hip acetabular component position affects component loosening rates. Clin Orthop Relat Res. 1988;(228):79-87.

14. Hartofilakidis G, Stamos K, Karachalios T. Treatment of high dislocation of the hip in adults with total hip arthroplasty. Operative technique and long-term clinical results. J Bone Joint Surg Am. 1998;80:510-517.

15. Paavilainen T, Hoikka V, Solonen KA. Cementless total replacement for severely dysplastic or dislocated hips. J Bone Joint Surg Br. 1990;72:20511.

16. Shen B, Yang J, Wang L, Zhou ZK, Kang PD, Pei FX. Midterm results of hybrid total hip arthroplasty for treatment of osteoarthritis secondary to developmental dysplasia of the hip-Chinese experience. J Arthroplasty. 2009;24:1157-63.

17. Haddad FS, Masri BA, Garbuz DS, Duncan CP. Primary total replacement of the dysplastic hip. Instr Course Lect. 2000;49:23-39.

18. Li H, Wang L, Dai K, Zhu Z. Autogenous impaction grafting in total hip arthroplasty with developmental dysplasia of the hip. J Arthroplasty. 2013;28:63743.

19. Delimar D, Cicak N, Klobucar H, Pećina M, Korzinek K. Acetabular roof reconstruction with pedicled iliac graft. Int Orthop. 2002;26:344-8.

20. Fujiwara M, Nishimatsu H, Sano A, Misaki T. Acetabular roof reconstruction using a free vascularized fibular graft. J Reconstr Microsurg. 2006;22:349-52.

21. Inao S, Matsuno T. Cemented total hip arthroplasty with autogenous acetabular bone grafting for hips with developmental dysplasia in adults: the results at a minimum of ten years. J Bone Joint Surg Br. 2000;82:375-7.

22. Kim M, Kadowaki T. High long-term survival of bulk femoral head autograft for acetabular reconstruction in cementless THA for developmental hip dysplasia. Clin Orthop Relat Res. 2010;468:1611-20.
23. Delimar D, Bohacek I, Pecina M, Bicanic G. Acetabular roof reconstruction with pedicled iliac graft: ten years later. Int Orthop. 2014;38:199-201.

24. Delimar D. Comments about "Vascularised pedicled iliac crest graft for selected total hip acetabular reconstructions: a cadaver study" Surg Radiol Anat. 2004;26:426-7.

25. Delimar D, Bićanić G, Pećina M, Korzinek K. Acetabular roof reconstruction with pedicled iliac graft: early clinical experience. Int Orthop. 2004;28:319-20.

26. Shinar AA, Harris WH. Bulk structural autogenous grafts and allografts for reconstruction of the acetabulum in total hip arthroplasty. Sixteen-yearaverage follow-up. J Bone Joint Surg Am. 1997;79:159-68.

27. Kwong LM, Jasty M, Harris WH. High failure rate of bulk femoral head allografts in total hip acetabular reconstructions at 10 years. J Arthroplasty. 1993;8:341-6.

28. Mulroy RD, Harris WH. Failure of acetabular autogenous grafts in total hip arthroplasty. Increasing incidence: a follow-up note. J Bone Joint Surg Am. 1990;72:1536-40.

29. Bobyn JD, Stackpool GJ, Hacking SA, Tanzer M, Krygier JJ. Characteristics of bone ingrowth and interface mechanics of a new porous tantalum biomaterial. J Bone Joint Surg Br. 1999;81:907-14.

30. Shirazi-Adl A, Dammak M, Paiement G. Experimental determination of friction characteristics at the trabecular bone/porous-coated metal interface in cementless implants. J Biomed Mater Res. 1993;27:167-75.

31. Siegmeth A, Duncan CP, Masri BA, Kim WY, Garbuz DS. Modular tantalum augments for acetabular defects in revision hip arthroplasty. Clin Orthop Relat Res. 2009;467:199-205.

32. Malizos KN, Bargiotas K, Papatheodorou L, Hantes M, Karachalios T. Survivorship of monoblock trabecular metal cups in primary THA : midterm results. Clin Orthop Relat Res. 2008;466:159-166.

33. Abeyta PN, Namba RS, Janku GV, Murray WR, Kim HT. Reconstruction of major segmental acetabular defects with an oblong-shaped cementless prosthesis: a long-term outcomes study. J Arthroplasty. 2008;23:247-253.

34. Dunn HK, Hess WE. Total hip reconstruction in chronically dislocated hips. J Bone Joint Surg Am. 1976;58:838-845.

35. Hartofilakidis G, Stamos K, Ioannidis TT. Low friction arthroplasty for old untreated congenital dislocation of the hip. J Bone Joint Surg Br. 1988;70:182-186.

36. Hartofilakidis G, Yiannakopoulos CK, Babis GC. The morphologic variations of low and high hip dislocation. Clin Orthop Relat Res. 2008;466:820824.

37. Dorr LD, Tawakkol S, Moorthy M, Long W, Wan Z. Medial protrusio technique for placement of a porous-coated, hemispherical acetabular component 
without cement in a total hip arthroplasty in patients who have acetabular dysplasia. J Bone Joint Surg Am. 1999;81:83-92.

38. Lai KA, Liu J, Liu TK. Use of iliofemoral distraction in reducing high congenital dislocation of the hip before total hip arthroplasty. J Arthroplasty. 1996;11:588-93.

39. Holinka J, Pfeiffer M, Hofstaetter JG, Lass R, Kotz RI, Giurea A. Total hip replacement in congenital high hip dislocation following iliofemoral monotube distraction. Int Orthop. 2011;35:639-45.

40. Li X, Sun J, Lin X, Xu S, Tang T. Cementless total hip arthroplasty with a double chevron subtrochanteric shortening osteotomy in patients with Crowe type-IV hip dysplasia. Acta Orthop Belg. 2013;79:287-92.

41. Reikeraas O, Lereim P, Gabor I, Gunderson R, Bjerkreim I. Femoral shortening in total arthroplasty for completely dislocated hips: 3-7 year results in 25 cases. Acta Orthop Scand. 1996;67:33-36.

42. Yasgur DJ, Stuchin SA, Adler EM, DiCesare PE. Subtrochanteric femoral shortening osteotomy in total hip arthroplasty for high-riding developmental dislocation of the hip. J Arthroplasty. 1997;12:8808.

43. Masonis JL, Patel JV, Miu A, Bourne RB, McCalden R, Macdonald SJ, Rorabeck $\mathrm{CH}$. Subtrochanteric shortening and derotational osteotomy in primary total hip arthroplasty for patients with severe hip dysplasia: 5-year follow-up. J Arthroplasty. 2003;18:68-73.
44. Sener N, Tözün IR, Aşik M. Femoral shortening and cementless arthroplasty in high congenital dislocation of the hip. J Arthroplasty. 2002;17:41-8.

45. Kawai $T$, Tanaka C, Ikenaga $M$, Kanoe $H$. Cemented total hip arthroplasty with transverse subtrochanteric shortening osteotomy for Crowe group IV dislocated hip. J Arthroplasty. 2011;26:229-35.

46. Bruce WJ, Rizkallah SM, Kwon YM, Goldberg JA, Walsh WR. A new technique of subtrochanteric shortening in total hip arthroplasty: surgical technique and results of 9 cases. J Arthroplasty. 2000;15:617-26.

47. Togrul E, Ozkan C, Kalaci A, Gülşen M. A new technique of subtrochanteric shortening in total hip replacement for Crowe type 3 to 4 dysplasia of the hip. J Arthroplasty. 2010;25:465-470.

48. Koulouvaris P, Stafylas K, Sculco T, Xenakis T. Distal femoral shortening in total hip arthroplasty for complex primary hip reconstruction. A new surgical technique. J Arthroplasty. 2008;23:992-8.

49. Goran Bicanic, Katarina Barbaric, Ivan Bohacek, Ana Aljinovic, andDomagoj Delimar Current concept in dysplastic hip arthroplasty: Techniques for acetabular and femoral reconstruction World $\mathbf{J}$ Orthop. 2014;5(4): 412-24.

Cite this article as: Kumar EGM, Kumar GMY, Noorudheen M. Challenges and outcome of total hip arthroplasty in patients with developmental dysplasia of the hip: a clinical series with a spectrum of disease manifestation and technical notes. Int J Res Orthop 2018;4:333-41. 